deans point out that they simply have to expand their research facilities to provide adequate laboratory space for their existing researchers, whose work is now hampered by overcrowding. "Our biggest problem is space," says James Pittman, dean of medicine at the University of Alabama at Birmingham, where some $\$ 90$ million has been invested in new biomedical research facilities over the past decade. "There are horrible fights. We see no way to slow down."

Kern Wildenthal, president of the Southwestern Medical Center at the University of Texas, where annual external research funding grew fivefold during the 1980 s, says that "it's unwise for any university to expand on the assumption that quality will follow". But Southwestern urgently needs more than 30,000 square metres of additional research space, he says.

Nevertheless, some biomedical research centres are expanding even though they have no immediate need for any extra research space. The growth of Jefferson Medical College in Philadelphia (see panel) is one example, but it is by no means exceptional. "We will be recruiting new faculty and developing new programmes," says Arthur Asbury, vice dean for research at the University of Pennsylvania Medical School.

Why are some biomedical research centres behaving in this seemingly rash manner? Alabama's Pittman believes he has the answer: "I think you need a critical mass to do research. Smaller schools will have a difficult time competing." Even if the University of Alabama at Birmingham did not need to expand to ease its overcrowding problem, the expansion would continue, he suggests. "I don't think we would willingly become one of the have-nots." Penn's Asbury agrees: "Less developed institutions tend to wither in time of drought."

So in the current harsh financial environment, it seems that the US biomedical research enterprise may be destined to undergo its own version of evolution by natural selection, with the weakest schools going to the wall. If that is the case, then quality US biomedical research will, over the next few years, become increasingly concentrated into a small number of centres of excellence. That in itself may be no bad thing, but AAHC's Bulger is concerned that the transitional period would see an excessive, and wasteful, movement of researchers among institutions.

If the evolutionary analogy holds true, however, the patrician voices of AAMC and AAHC are unlikely to be heeded: no darwinian theorist would predict that any individual research centre should jeopardize its survival by forgoing its own expansion to serve the common good.

Peter Aldhous

\section{Hazy hazy days}

\section{Washington}

ASTRONAUTS aboard the US space shuttle Atlantis report that the Earth's atmosphere seems much hazier at present than on their previous trips into orbit. In a televised press conference last week, mission specialist Shannon Lucid and flight commander John Blaha speculated that the oil well fires in Kuwait or the recent volcanic eruptions in the Pacific might be

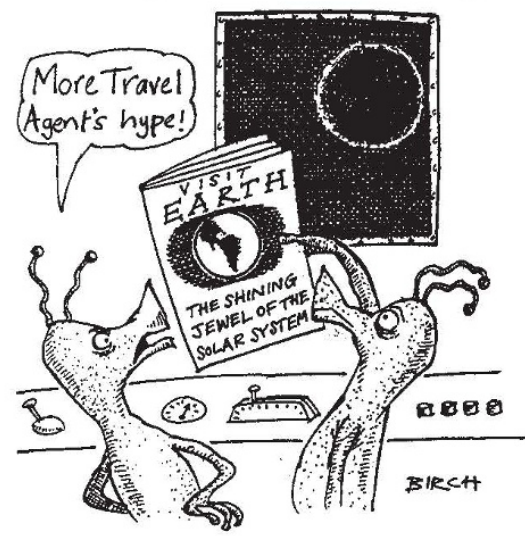

to blame. But according to Vic Whitehead, a geoscientist at the National Aero nautics and Space Administration's Johnson Space Flight Center, a more likely cause is a recent spate of dust storms in Africa.

The current Atlantis mission includes a survey of stratospheric ozone, with a device called the shuttle solar backscatter ultraviolet instrument. These data will be used to calibrate the ozone mapping instruments on orbiting satellites, but should also help to reveal any ozone depletion caused by the Kuwaiti fires or recent volcanic activity.

P.A.

\section{Birth rate shows signs of decline \\ Washington}

THE birth rate in developing countries has slowed over the past decade, according to results described at a conference in Washington last week. Martin Vaessen, head of the Demographic and Health Surveys (DHS) project, a huge study encompassing some 25 developing countries and funded by the US Agency for International Development, says the results indicate that the population control message is beginning to be heard. The most encouraging results from the conference, called to review the past five years' work of DHS, is the finding that the birth rate in many African countries has fallen over the past decade, Vaessen says. In Kenya, for example, the average number of children born to each woman has fallen from 8.2 to 6.5 over the past 12 years. Although the birth rate in Latin America has been falling since the late 1960 s, the African trend is more recent.
But Vaessen warns that much remains to be done, with no signs of a declining birth rate in some other African states, such as Mali, Liberia and Senegal. And even in developing countries where the birth rate is falling, reduced mortality means population growth is still a problem. P.A

\section{Less animal testing}

\section{London}

BRITISH companies slashed their use of animals for testing cosmetics and household products by two-thirds last year, part of an increasing trend toward alternatives to animal testing of consumer goods, according to a new government report on UK research animal use. The figures are the latest sign of a decrease in the number of procedures carried out in the United Kingdom on living animals, a total that fell from $\mathbf{3 . 3 2}$ million to $\mathbf{3 . 2 1}$ million last year, part of a 15-year decline from a peak of nearly 6 million in the mid-1970s.

One of the few areas in which animal research is increasing is in medical research on non-human primates, which climbed 13 per cent from last year to a total of 704 experiments. Although the Royal Society for the Prevention of Cruelty to Animals commended the reduction in total number of scientific procedures, it lumped it with another 'positive' trend that UK scientists may not feel so good about: a decrease in the number of British research establishments, from 375 to 366.

\section{Additional sums}

\section{London}

BRITAIN'S principal research council intends to request a funding increase for its mathematics division after an advisory panel found that the UK mathematics funding is "dangerously inadequate" and that the country is missing opportunities to capitalize on recent advances in the discipline.

Sir Mark Richmond, chairman of the Science and Engineering Research Council (SERC), announced last week that, as recommended by the panel, the council would request a 50 per cent increase in the number of mathematics research student scholarships and a tripling of postdoctoral fellowships in the agency's bid for future funds.

Although that request is subject to government approval, SERC intends to take matters into its own hands by allocating more student fellowships to mathematics next year, although the exact number has not yet been announced. In October, the council also plans to release a request for new proposals in applied solutions to non-linear problems, part of the nonlinear research initiative started last year. Total funding for that effort has not been set, but officials are hoping for as much as $£ 1$ million. 